\title{
Experimental study of the impingement process of a liquid droplet upon a corrugated cardboard surface
}

\author{
X. Zhou \\ FM Global, Norwood, MA, USA
}

\begin{abstract}
A water transport model is one of the key components in fire modelling of sprinkler protection of solid combustible commodities. In order to provide preliminary measurements to validate and improve the water film transport model, a series of measurements were conducted to study the impingement process of a liquid droplet upon a corrugated cardboard surface. The impact surface is a wetted cardboard covered by a water film with different thicknesses. Two liquids with different surface tension, droplet sizes and impact velocities were investigated. The sizes and velocities of the splashed droplets were measured by a laser-based Shadow-Imaging system. The evolution of the water film thickness and the contact angle with the number of impact droplets was measured. The results show that the splashing fraction increases with the film thickness and the Weber number. The distribution of cumulative volume fraction of splashed droplets was correlated with the normalized droplet size using a Rosin-Rammler function. The volume-median droplet diameter was expressed as a function of the relative film thickness and the Weber number. The maximum velocity magnitude of a splash droplet was correlated to its size, the Weber number and the relative film thickness. These test data and empirical correlations can be incorporated into a numerical model to simulate the splashing fraction, size and velocity distributions of the splashed droplet.
\end{abstract}

Keywords: cardboard, splashing, water droplet, fire protection.

\section{Introduction}

For the past several years, numerical simulations of sprinkler protection have shown promising prospects for large fires in a rack storage configuration. This is 
largely due to FM Global's ongoing effort of developing a new computational code, FireFOAM, to model water-based fire protection of corrugated cardboard boxes stored in a rack storage configuration [1]. The FireFOAM code requires a water film transport model to simulate impingement, splashing, surface flow and film separation processes. A film transport model has been developed; however, a literature review showed that no experimental data existed to validate the model. The current film transport model requires experimental guidance and certain empirical inputs, such as, splashing fraction.

In a sprinkler-based fire protection system, part of the water droplets from a sprinkler spray can penetrate through the fire plume and impinge on the surface of the fuel such as a corrugated cardboard box. Droplet impingement can also occur during water transport through a rack storage arrangement. Regarding a single droplet impinging on a surface, three different outcomes of this impact are possible: (1) for relatively low momentum impacts, the droplet may deposit on the surface and form a water film, (2) for relatively high momentum impacts, the impinging droplet may splash, leading to a cloud of smaller secondary droplets around the point of impingement, and (3) for special surface conditions, such as very hot surfaces, the droplet may be completely reflected. These outcomes can change the amount of water transported along the fuel surface. Since water cooling of a fuel surface is the dominant mechanism for sprinkler protection, the amount of water droplets deposited on the fuel surface is of considerable importance.

Droplet-surface interaction is a complex process. The possible outcomes of deposition, splashing or rebound are controlled by many factors including liquid droplet properties (i.e., density, surface tension and viscosity), droplet size, droplet impact velocity and contact angle, and fuel surface characteristics such as roughness, softness, wettability, temperature, and whether the surface is dry or wet. The complicated physics associated with all these factors are not yet well understood despite numerous experimental and theoretical studies that have been performed in the past [2-9]. The literature review also showed that no measurements were reported on spray droplets impinging on a corrugated cardboard box, which is typically used for rack storage of commodities in various industries.

The goal of the present investigation is to provide experimental data in a form suitable to validate and improve the film transport model on corrugated cardboard surfaces used in FireFOAM. For this purpose, the size and velocity distributions of the secondary droplets and the splashing mass fraction were measured in a range of parameters relevant to sprinkler protection. The droplet size, impact velocity and liquid surface tension were varied. The impact surfaces were a wetted cardboard covered by a water film with different thicknesses. A laser-based Shadow-Imaging system was employed, in addition to other measurement and visualization techniques. Empirical correlations were developed to describe the size and velocity distributions of the splashed droplets. 


\section{Experimental setup}

The liquid droplets were generated using a syringe pump that was controlled to dispense the liquid at a steady rate of $100 \mathrm{ml} /$ hour. The droplet was formed the tip of the needle and detached under its own weight. The droplet size was changed by using different needles. The height of the needle above the surface was adjusted to change the droplet impingement velocity. To evaluate the effect of the liquid surface tension on the impingement, two liquids with different surface tensions were used. One was deionized (DI) water that has a surface tension of $0.0728 \mathrm{~N} / \mathrm{m}$ at $20{ }^{\circ} \mathrm{C}$. The other liquid was a blend of Ethanol $(11.1 \%$ in mass fraction) and DI water. The surface tension of the blend is $0.047 \mathrm{~N} / \mathrm{m}$ at $20^{\circ} \mathrm{C}$ [10], which is $35.4 \%$ smaller than that of DI water. The density of the blend is $0.974 \mathrm{~g} / \mathrm{cm}^{3}$, as calculated from the mass composition. It is $2.3 \%$ lower than that of DI water $\left(0.998 \mathrm{~g} / \mathrm{cm}^{3}\right)$ at $20^{\circ} \mathrm{C}$. The kinematic viscosity of the blend was estimated to be $1.047 \times 10^{-6} \mathrm{~m}^{2} / \mathrm{s}$ using the Refutas equation [11]. This value is $4.3 \%$ higher than that of DI water $\left(1.004 \times 10^{-6} \mathrm{~m}^{2} / \mathrm{s}\right)$ at $20^{\circ} \mathrm{C}$.

Figure 1 shows a solid surface sample that was cut from a triple-wall corrugated cardboard. Cardboard is a paper-based material consisting of fluted corrugated sheets, intermediate plies and flat linerboards. It is widely used in the manufacturing of carton boxes and shipping containers. The roughness, softness and wettability of the cardboard surface are expected to be different from that of other materials such as metal, glass or ceramic, which have been studied extensively in literature. The water absorption propensity of four different corrugated cardboards was measured by Jayaweera and Yu [12]. In general, the water absorption rate for a corrugated board increases linearly with water flux, and is slightly affected by the surface characteristics and morphology of the board.
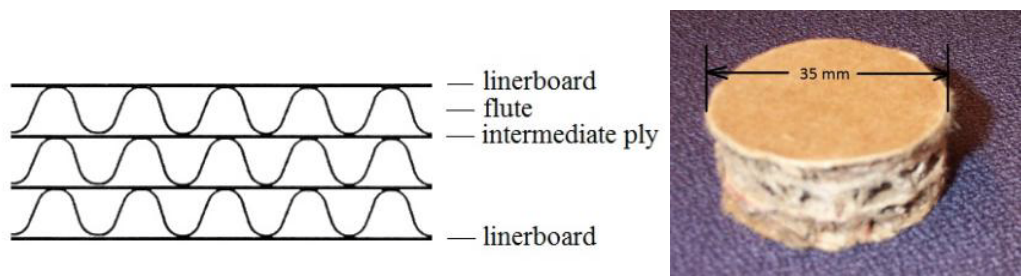

Figure 1: $\quad$ Illustration of a triple-wall corrugated cardboard and a sample used in the current test.

A small cardboard sample, $35 \mathrm{~mm}$ in diameter and $14 \mathrm{~mm}$ in thickness, was used in this work for the splashing measurement. Based on the experimental observation, this sample diameter was selected to collect the deposited liquid but minimize the influence to the splashed liquid. A falling liquid droplet would impinge at the center of the cardboard sample. The sample surface investigated in this paper was wetted either by the impingement of a number of liquid droplets or covered by a liquid film with a pre-defined thickness. 
A high-speed digital camera set at 1000 frames/s with an exposure time of $250 \mu \mathrm{s}$ was used to observe the droplet impingement process. Each image has a pixel resolution of $1504 \times 1128$. The physical size of the camera's field of view was adjusted to be $64 \times 48 \mathrm{~mm}$. This camera can visualize the entire impingement process; however, it is not suitable for measuring droplet size and velocity, mainly due to the image of a moving droplet being exposed for a long time.

A laser-based shadow-imaging system was used in this work to measure droplet size and velocity. This system was previously used to characterize sprinkler sprays [13]. The shadow-imaging technique relies on both high resolution images and pulsed backlight illumination. The light source is a double-cavity-frequency Nd:YAG laser, which provides two light pulses at $532 \mathrm{~nm}$ wavelength with a pulse energy of about $120 \mathrm{~mJ}$. The light source passes through an optical diffuser to create uniform light intensity at the measurement location. The detection system consists of a 14-bit dual-frame CCD camera with a $2048 \times 2048$ pixel resolution and a $12 \mathrm{X}$ zoom lens. Using a short laser pulse (less than $16 \mathrm{~ns}$ ) as illumination, the exposure time is so short that a moving droplet is "frozen" and the droplet size can be quantified. A two-dimensional velocity is measured from the shift distance of droplets recorded in a pair of images with a known time interval. A double-pulse laser combined with a double-frame camera allows this technique for the investigation of droplet size, velocity and size-velocity dependency.

The current camera's field of view was $31.6 \times 31.6 \mathrm{~mm}$ after calibrating the detection system. The minimum droplet size that could be detected was $80 \mu \mathrm{m}$. During the test, the digital camera focused on the impingement location and the impact droplet fell through the vertical focal plane. The statistical results were calculated from the attributes of all the detected droplets. One of the characteristic droplet diameters is the volume-median droplet diameter, $d_{v 50}$, which denotes that $50 \%$ of the cumulated water volume is represented by droplets having a diameter smaller than $\mathrm{d}_{\mathrm{v} 50}$.

The maximum recording rate of the current shadow-imaging system is $15 \mathrm{~Hz}$, which is too low to capture the entire impingement process. Therefore, the system was upgraded by installing a droplet detector. When a droplet is generated and is detected by the detector, an electrical signal is sent to the shadow-imaging system. The laser and camera are then triggered to capture a pair of images at a pre-determined reference time. Because of the low recording rate, only one pair of instant images can be captured during the impingement process for one droplet at a time. By changing the reference time, the system can capture the entire droplet impingement process, but the recordings have to be made over several cycles.

For an upright sprinkler with a K-factor of $162 \mathrm{lpm} / \mathrm{bar}^{1 / 2}$ operated at $0.76 \mathrm{bar}$, it was observed, from previous measurements, that the maximum droplet size could be $4.5 \mathrm{~mm}$ with a speed of $5.4 \mathrm{~m} / \mathrm{s}$ [13]. Therefore a large single droplet was selected for the current study. For DI water, two sizes of droplets were generated with diameters of $4.3 \pm 0.1$ and $2.9 \pm 0.1 \mathrm{~mm}$ from different needles. For the blend liquid of Ethanol plus DI water, the generated droplet size was $4.2 \pm 0.1$ $\mathrm{mm}$. The impact droplet velocity was varied in a range from 1.5 to $3.7 \mathrm{~m} / \mathrm{s}$ by 
adjusting the falling height from 0.11 to $0.76 \mathrm{~m}$. The size and velocity of droplets generated from the needle were also measured by the shadow-imaging system.

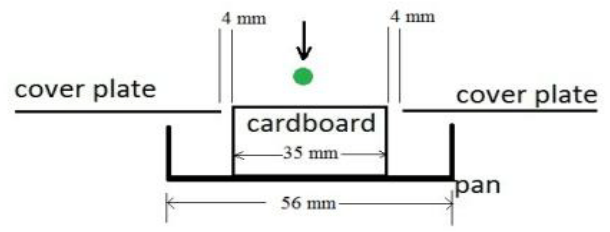

Figure 2: A sketch of an experimental setup to measure the splashing mass fraction.

The experimental setup illustrated in Figure 2 was designed to measure the splashing mass fraction. The cardboard sample was placed in the center of a pan and a cover plate. There is a gap of about $4 \mathrm{~mm}$ between the sample and the cover plate. The cover plate is $2 \mathrm{~mm}$ lower than the cardboard sample surface. When a falling droplet impinges on the cardboard surface, the splashed liquid is collected by the plate, and the deposited liquid is collected by the cardboard and the pan. The splashing mass fraction is calculated as:

$$
Y_{\text {splash }}=\frac{m_{\text {impinge }}-m_{\text {deposit }}}{m_{\text {impinge }}}
$$

where $m_{\text {impinge }}$ is the mass of the impact droplet, and $m_{\text {deposit }}$ is the mass of liquid deposited on the cardboard sample. A precision weighing balance with a capacity of $210 \mathrm{~g}$ and a standard deviation of $0.1 \mathrm{mg}$ was used to measure the mass difference.

\section{Results and discussions}

\subsection{Splashing pattern}

After the first liquid droplet impacts on a dry cardboard surface, a portion of liquid deposits on the surface and the surface is wetted. When a second droplet

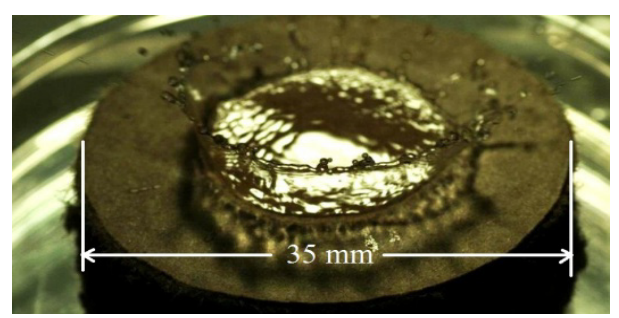

Figure 3: Image of water droplet $\left(\mathrm{d}_{\mathrm{I}}=4.3 \mathrm{~mm}, \mathrm{~V}_{\mathrm{I}, \mathrm{n}}=3.1 \mathrm{~m} / \mathrm{s}\right)$ impingement upon a wetted surface. 
impinges normal to the surface, Figure 3 shows the image of this event captured at $\mathrm{t}=5 \mathrm{~ms}$ by a high-speed camera, an irregular crown-like sheet is produced and splashed droplets are ejected continuously along the rim as the crown grows upward. The water film thickness, contact angle, splashing fraction, droplet size, velocity magnitude and direction were then measured on a wetted surface.

\subsection{Water film thickness and contact angle}

When successive droplets impact continuously on a cardboard surface, a water film is formed on the surface. Figure 4 shows the evolution of the water film thickness and the contact angle after successive droplet impingement. The film thickness was measured as the difference between the cardboard surface and the top surface of the film. The contact angle was measured as the angle from the horizontal of the line tangent to the liquid-air interface where it meets the solid surface. The data in Figure 4 are for an impact droplet with a size of $4.3 \mathrm{~mm}$ and two different impact velocities of 1.5 and $2.7 \mathrm{~m} / \mathrm{s}$. At a low impact velocity, there is no splashing and the water film extends to the edge of the cardboard sample. When the film expands to the edge, more water can be retained on the cardboard because of the sample's edge effect and the contact angel is bigger. Figure 4 shows that the maximum film thickness is $3.3 \mathrm{~mm}$ and the contact angle is $75^{\circ}$. When the impact velocity is increased, the water film is significantly disrupted. Figure 4 shows that the water film is thinner and the contact angle is smaller for an impact velocity of $2.7 \mathrm{~m} / \mathrm{s}$.
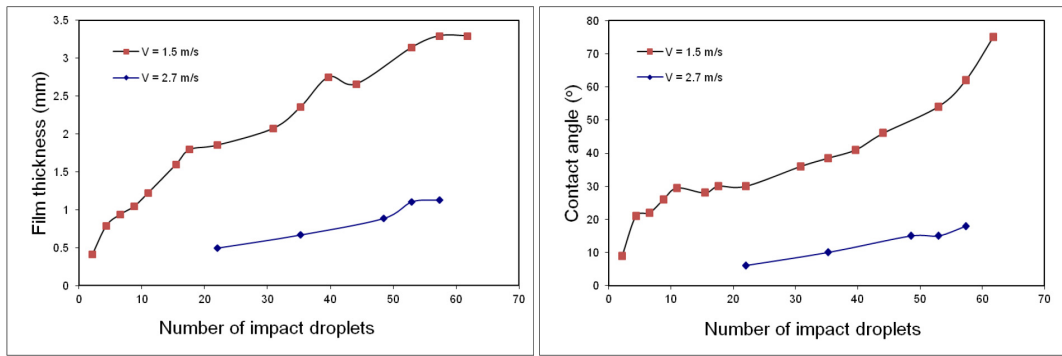

Figure 4: Evolution of the water film thickness (left) and the contact angle (right) with the number of impact droplets measured respectively for one droplet size $(4.3 \mathrm{~mm})$ and two impact velocities (1.5 and $2.7 \mathrm{~m} / \mathrm{s})$.

\subsection{Splashing fraction}

The splashing fraction was measured by the impingement of a number of droplets continuously on a cardboard surface and then the measurement of the mass difference. During this process, a liquid film was formed but its thickness varied. The splashing fraction on a wetted surface was calculated by excluding the effect of the first droplet on a dry surface. Since there are many parameters 
affecting the outcome of a droplet impact on a surface, a droplet Weber number is defined to represent the ratio of inertia to surface tension forces as:

$$
\mathrm{We}=\rho \mathrm{V}_{\mathrm{I}, \mathrm{n}}^{2} \mathrm{~d}_{\mathrm{I}} / \sigma
$$

where $\rho$ is the liquid density, $\mathrm{V}_{\mathrm{I}, \mathrm{n}}$ is the surface-normal impact velocity of the impinging droplet, $\mathrm{d}_{\mathrm{I}}$ is the diameter of the impinging droplet, and $\sigma$ is the liquid surface tension. Figure 5 shows the average splashing fractions measured for two liquids and different droplet sizes as a function of the Weber number. The error bars represent the standard deviations. To measure the mass difference, 20 big droplets (i.e., $4.3 \mathrm{~mm}$ ) or 100 small droplets (i.e., $2.9 \mathrm{~mm}$ ) were discharged during each test. Generally, the splashing fraction increases with Weber number.

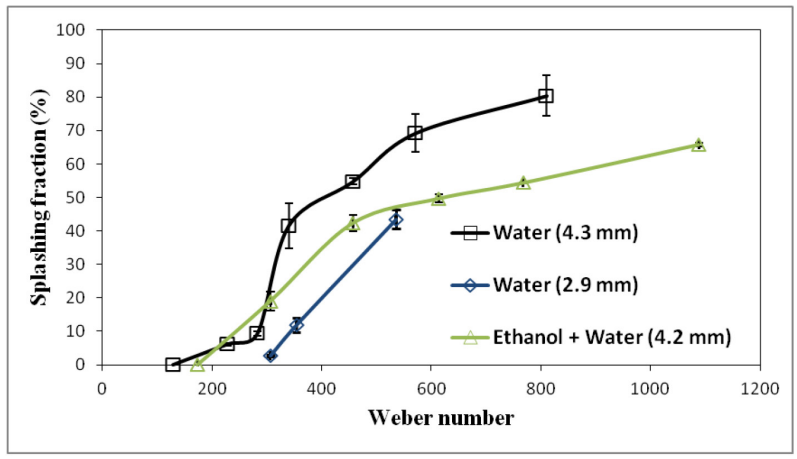

Figure 5: $\quad$ Splashing fraction versus Weber number measured for two liquids and different droplet sizes after 20 big droplets or 100 small droplets impinged continuously on a cardboard surface.

Following the above measurements, the radial mass distribution of splashed droplets around the impingement center was also measured. The cover plate shown in Figure 2 was divided into five annular zones with six radii of 22, 40, 60, 89, 134 and $190 \mathrm{~mm}$. The first annulus near the impingement center is in the radial range from 22 to $40 \mathrm{~mm}$, and the fifth annulus is from 134 to $190 \mathrm{~mm}$. After successive droplets impinged continuously on the cardboard surface, the droplets splashed in each annulus were collected carefully using a tissue paper. The mass of splashed droplets in each annulus was then measured as the mass difference of the tissue paper, and was expressed as the mass fraction relative to the impact droplets. Figure 6 shows the radial distribution of the average splashing mass fractions measured in the five annular zones for three Weber numbers. To measure the mass difference, 50 big water droplets $\left(\mathrm{d}_{\mathrm{I}}=4.3 \mathrm{~mm}\right)$ were discharged during each test. The test data in the first annulus is more scattered because the collection of splashed droplets is affected by the deposited liquid. Generally, the figure shows that the splashing fraction decreases with the radial distance and increases with Weber number in the external zones. It was also observed from the test that some splashed droplets traveled too far to be collected by the cover plate. For the current cover plate, the average mass 
fractions of non collected droplets are $2.4 \pm 1 \%$ at $\mathrm{We}=340,16.3 \pm 2 \%$ at $\mathrm{We}=570$ and $29.9 \pm 1 \%$ at $\mathrm{We}=810$.

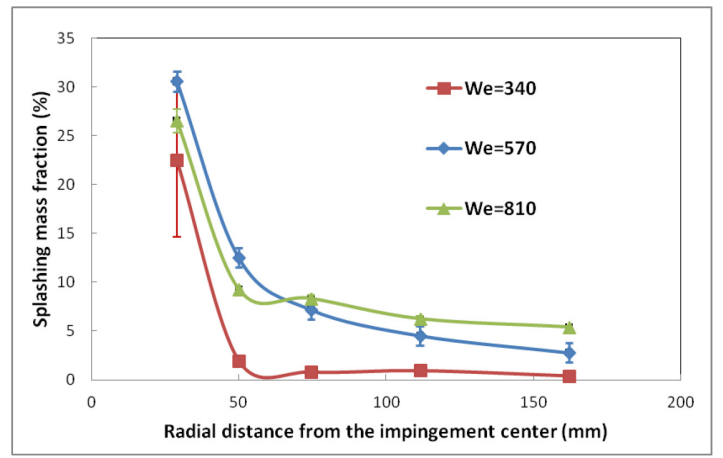

Figure 6: Radial mass distribution of splashed droplets measured for three Weber numbers after 50 big droplets impinged continuously on a cardboard surface.

It is observed from Figure 5 that the splashing fractions for the three test conditions are not well correlated with the Weber number. This is because the water film thickness is not constant during the entire impingement process. As a result, a separate set of tests was carried out to examine the effect of the film thickness on the droplet impingement. To form a liquid film on the cardboard with a pre-defined thickness, a circular container was made by wrapping a cardboard sample with tape. The container's base is the cardboard surface and its wall is the tape with different heights of 2,3 and $5 \mathrm{~mm}$. A liquid film was formed by filling the container with a given amount of liquid. The liquid film was about $1 \mathrm{~mm}$ lower than the container's rim and three film thicknesses of 1,2 and $4 \mathrm{~mm}$ were examined. Because liquid can be absorbed by the cardboard on the surface and along the sample edge, one experimental challenge was that the liquid film would disappear after some time. For example, a $1 \mathrm{~mm}$ water film would disappear after about seven minutes. For the blend liquid (Ethanol + Water), it was not easy to maintain a constant film thickness due to rapid absorption of the liquid into the corrugated and the test results were not repeatable. Therefore, only the water film was investigated in this work. To maintain a pre-defined water film thickness, the container was filled just before the beginning of each test.

Figure 7 shows the average splashing fraction versus the relative film thickness measured for water droplets $\left(d_{I}=4.3 \mathrm{~mm}\right)$ with three Weber numbers. The relative film thickness of $\delta / d_{I}$ is the film thickness divided by the droplet diameter. For a low Weber number (300-600), Figure 7 shows that the splashing fraction decreases as the relative film thickness increases from 0.2 to 0.9 . As the Weber number increases to 810, a shift in the peak splashing fraction is observed with relative film thickness. At this impact condition ( $W e=810$ and $\delta / d_{I}=0.46$ ), a few splashing fractions larger than $100 \%$ were also measured, which means that 
the splashed droplets contain the impact droplet and additional amount of water from the water film. Generally, Figure 7 shows that the splashing fraction decreases as the relative film thickness increases. Under the same impact condition, the results in Figure 7 also show that the mechanisms leading to splashing on a thin surface film $\left(\delta / \mathrm{d}_{\mathrm{I}}=0.2\right)$ and a thick surface film $\left(\delta / \mathrm{d}_{\mathrm{I}} \cong 1\right)$ are different. For a thin film, the spreading film coming from the droplet deformation is mostly deflected by the resistance of the surface film so that a crown is formed. The cardboard beneath the thin film influences the droplet deformation and the film spreading. For a thick film, there are more complex phenomena such as cavity formation, bubble entrapment and jetting. The droplet deformation and splashing are more influenced by the surface film rather than the cardboard. From the point of view of energy, most of the impact energy on a thin film is transferred to the spreading film and the splashed droplets. However, a thick film can absorb most of the impact energy and generate a big rising jet.

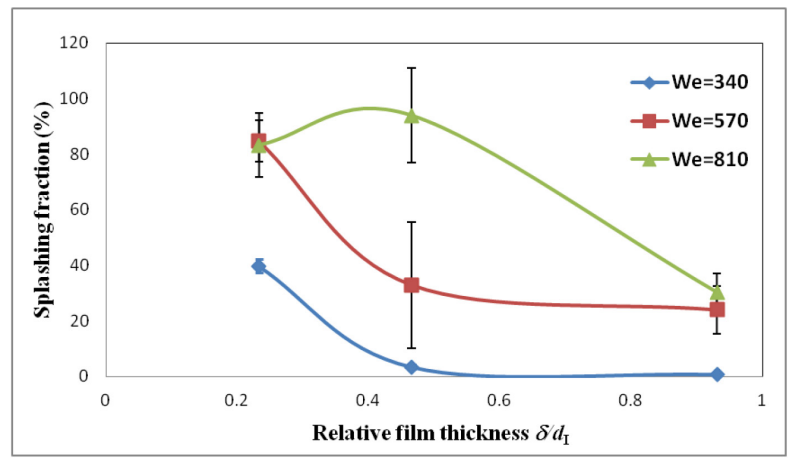

Figure 7: $\quad$ Splashing fraction versus relative film thickness measured for ten water droplets $\left(\mathrm{d}_{\mathrm{I}}=4.3 \mathrm{~mm}\right)$ impinging on a wetted cardboard surface with different Weber number.

\subsection{Size and velocity}

The size and velocity of splashed droplets were measured using the shadowimaging system for a water droplet impinging on a wetted cardboard with a predefined water film thickness. Figure 8 shows two shadow-images of splashed droplets captured at 5 and $15 \mathrm{~ms}$, respectively, after a water droplet impinges on a 4 -mm thick water film. The impact droplet had a diameter of $4.3 \mathrm{~mm}$ and a velocity of $3.7 \mathrm{~m} / \mathrm{s}$. The arrow in the figure represents the falling trajectory of the impact droplet. At the early stage of $\mathrm{t}=5 \mathrm{~ms}$, Figure 8 shows that many secondary droplets are splashing out from the crown. The initial splashing angle is about $40^{\circ}$ relative to the horizontal level. At the later stage, however, only a few big droplets splash out at an angle of $60^{\circ}$. This is because different mechanisms at different stages are creating secondary droplets. At the early stage, most of the secondary droplets may come from prompt splashing. As the crown grows 
upward at the later stages, those unstable fingers detach from the rim and break up into big droplets.
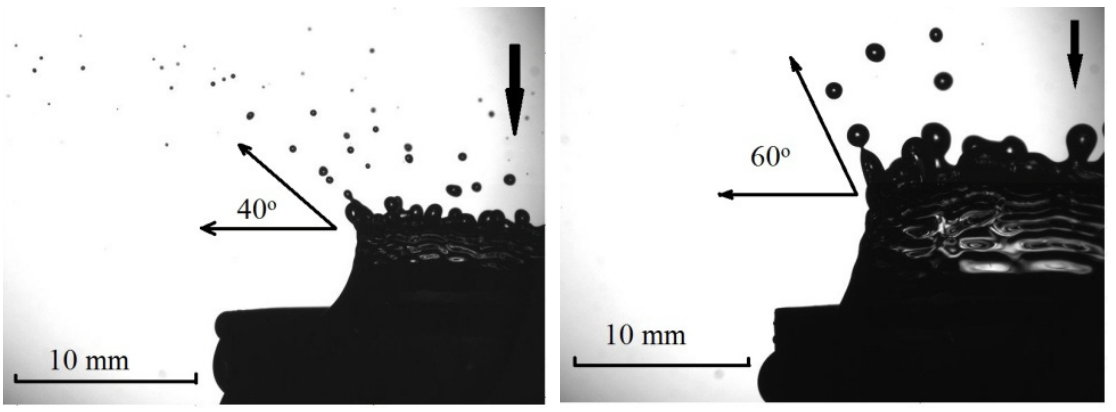

Figure 8: Shadow-images of splashed droplets captured at $\mathrm{t}=5 \mathrm{~ms}$ (left) and $\mathrm{t}=15 \mathrm{~ms}$ (right) after a water droplet $\left(\mathrm{d}_{\mathrm{I}}=4.3 \mathrm{~mm}\right.$ and $\left.\mathrm{V}_{\mathrm{I}, \mathrm{n}}=3.7 \mathrm{~m} / \mathrm{s}\right)$ impinging on a $4 \mathrm{~mm}$ thick water film surface.

The gross droplet size distribution was calculated from the measurements obtained at two times of 5 and 15 ms. Figure 9 shows the distributions of cumulative volume fraction (CVF) of splashed droplets versus a normalized droplet size of $d / d_{v 50}$, which were measured for three water film thicknesses and three Weber numbers. The Rosin-Rammler fitting function was used to correlate the droplet size distribution as:

$$
F(d)=1-\exp \left[-0.693\left(\frac{d}{d_{v 50}}\right)^{2.8}\right],
$$

where $F(d)$ is the CVF of splashed droplets with a diameter less than d. Under different impingement conditions, Figure 9 shows that the scattered data are well correlated by the fitting curve.

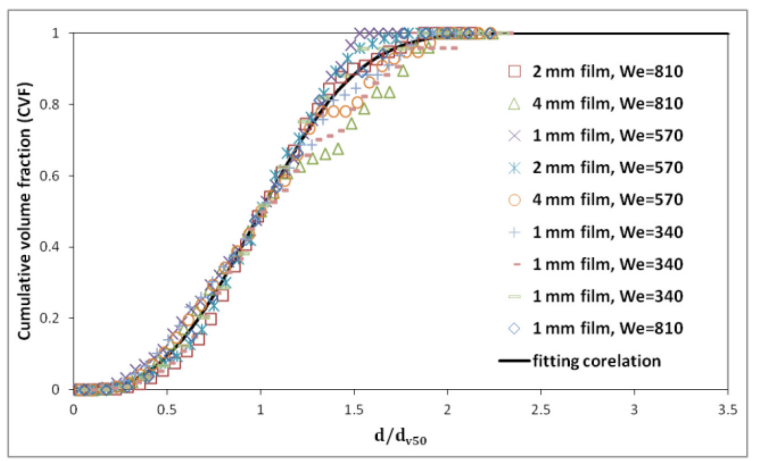

Figure 9: CVF distributions of splashed droplets fitted with a Rosin-Rammler function and measurements obtained from three water film thicknesses and three Weber numbers. 
The volume-median droplet diameter of $\mathrm{d}_{\mathrm{v} 50}$ is a variable at different impact conditions. Based on the measurements, an empirical function was developed to describe $\mathrm{d}_{\mathrm{v} 50}$ as:

$$
\frac{\mathrm{d}_{\mathrm{v} 50}}{\mathrm{~d}_{\mathrm{I}}}=0.018 \ln \left[\frac{\delta}{\mathrm{d}_{\mathrm{I}}} \mathrm{We}\right]+0.1,
$$

which is applicable for a water droplet impinging normal to a wetted cardboard surface in the current test range of $0.1<\delta / \mathrm{d}_{\mathrm{I}}<1$ and $500<\mathrm{We}<900$.

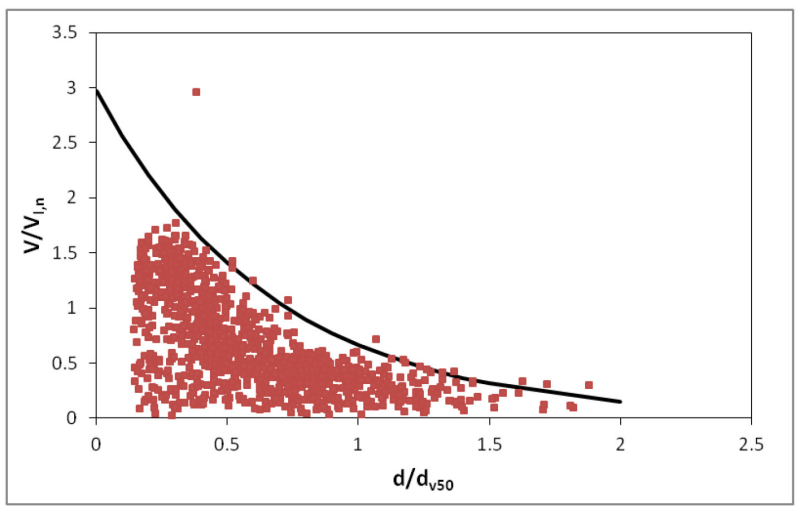

Figure 10: Scatter plot of normalized splash droplet velocity $\left(\mathrm{V} / \mathrm{V}_{\mathrm{I}, \mathrm{n}}\right)$ versus normalized droplet diameter $\left(\mathrm{d} / \mathrm{d}_{\mathrm{v} 50}\right)$ for a water droplet $\left(\mathrm{d}_{\mathrm{I}}=4.3\right.$ $\mathrm{mm}, \mathrm{V}_{\mathrm{I}, \mathrm{n}}=3.7 \mathrm{~m} / \mathrm{s}$ ) impinging on cardboard with a 1-mm water film.

The velocity distribution of a splashed droplet on wetted cardboard is complicated because its magnitude and direction vary at different times and impact conditions. Figure 10 shows a scatter plot of normalized splash droplet velocity magnitude $\left(\mathrm{V} / \mathrm{V}_{\mathrm{I}, \mathrm{n}}\right)$ versus normalized droplet diameter $\left(\mathrm{d} / \mathrm{d}_{\mathrm{v} 50}\right)$ for a water droplet $\left(\mathrm{d}_{\mathrm{I}}=4.3 \mathrm{~mm}, \mathrm{~V}_{\mathrm{I}, \mathrm{n}}=3.7 \mathrm{~m} / \mathrm{s}\right)$ impinging normal to a wetted cardboard surface with a 1-mm water film. A general trend is that small droplets tend to have a higher velocity. Some splashed droplet velocities are faster than the initial impact velocity. It was observed that the velocity scatter plots are similar for other impact conditions. Figure 10 also includes a solid curve that represents a possible maximum velocity magnitude $\left(\mathrm{V}_{\mathrm{m}}\right)$ for a droplet size. This curve can be expressed as a function:

$$
\frac{\mathrm{v}_{\mathrm{m}}}{\mathrm{V}_{\mathrm{I}, \mathrm{n}}}=\mathrm{C}_{\mathrm{t}}\left(-1.5 \frac{\mathrm{d}}{\mathrm{d}_{\mathrm{v} 50}}\right), 0<\frac{\mathrm{d}}{\mathrm{d}_{\mathrm{v} 50}}<3,
$$

which is used to correlate the maximum splashing velocity $\left(\mathrm{V}_{\mathrm{m}}\right)$ for a droplet size. The coefficient $C_{t}$ is correlated as a function of We and $\delta / d_{I}$ as:

$$
\mathrm{C}_{\mathrm{t}}=\left(-0.0023 \frac{\delta}{\mathrm{d}_{\mathrm{I}}}-0.0002\right)(\mathrm{We}-340)+3.3 \text {, }
$$

which is applicable for the current test range $0.2<\delta / \mathrm{d}_{\mathrm{I}}<1$ and $300<$ We $<900$. When the impact condition is given, the value of $\mathrm{V}_{\mathrm{m}}$ of a splashed droplet can be 
calculated. Assuming a uniform probability density, the droplet's velocity magnitude can be selected randomly in the range from 0 to $\mathrm{V}_{\mathrm{m}}$.

As shown in Figure 8, the flight direction of a splashed droplet varies at different stage and impact conditions. For a water droplet impinging normal to a wetted cardboard surface, the splashing angle relative to the horizontal ranges between $40^{\circ}$ and $60^{\circ}$. Therefore, the velocity vector's direction can be selected randomly in this angle range.

\section{Summary and conclusion}

An experimental study was conducted to investigate the impingement process of a liquid droplet upon a wetted cardboard surface. The water film thickness, contact angle, splashing fraction, droplet size, velocity magnitude and direction were measured under various impact conditions. Empirical correlations were introduced to describe the size and velocity distributions of the splashed droplets. These data and correlations can be incorporated into numerical models to simulate the droplets splashing on a wetted cardboard surface. The experimental conditions examined in this work are limited to single droplet. The splashing behaviours of a cloud of droplets, such as that generated by an automatic fire sprinkler, should be the subject of further investigations.

\section{Acknowledgements}

This study was funded by FM Global in its sprinkler technology research program. The author is grateful to Regis Bauwens, Stephen D'Aniello, Blair Swinnerton and Geary Yee for their assistance in the preparation of the measurement setup. The discussions with Yibing Xin, Hong-Zeng Yu, Karl Meredith, Christopher Wieczorek and Franco Tamanini are also appreciated.

\section{References}

[1] Wang, Y., Chatterjee, P. and de Ris, J.L., Large eddy simulation of fire plumes, Proceedings of the Combustion Institute, Volume 33, Issue 2, 2011, pp. 2473-2480, and the web page http://www.fmglobal.com /modeling.

[2] Mundo, C., Sommerfeld, M., Tropea, C., Droplet-wall collisions: experimental studies of the deformation and breakup process. Int. J. Multiphase Flow, Vol. 21, 1995, pp. 151-173.

[3] Rioboo, R., Marengo, M. and Tropea, C., Time evolution of liquid drop impact onto solid, dry surfaces, Experiments in Fluids, Vol. 33, 2002, pp. 112-124.

[4] Josserand, C., Lemoyne, L., Troeger, R., and Zaleski, S., Droplet impact on a dry surface: triggering the splash with a small obstacle, J. Fluid Mech., Vol. 524, 2005, pp. 47-56. 
[5] Harlow, F.H. and Shannon, J.P. The Splash of a Liquid Drop, Journal of Applied Physics, Vol. 38, 1967, pp. 3855-39867.

[6] Macklin, W.C., Metaxas, G.J., Splashing of drops on liquid layers. J. Appl. Phys., Vol. 47, 1976, pp. 3963-3970.

[7] Rein, M., Phenomena of liquid drop impact on solid and liquid surfaces. Fluid Dynamics Research, Vol. 12, 1993, pp. 61-93.

[8] Cossali, G.E., Coghe, A., Marengo, M., The impact of a single drop on a wetted surface, Experiments in Fluids, Vol. 22, 1997, pp. 463-472.

[9] Manzello, S.L. and Yang, J.C., An experimental study of a water droplet impinging on a liquid surface, Experiments in Fluids, Vol. 32, 2002, pp. 580-589.

[10] Dean, J. A. and Lange, N. A., Lange's Handbook of Chemistry, pp 16611665, ISBN 0070161909, New York: McGraw Hill Book Company (1967, 11th ed.).

[11] Maples, R. E., Petroleum Refinery Process Economics (2000, 2nd ed.). Pennwell Books. ISBN 0878147799.

[12] Jayaweera, T.M. and Yu, H-Z, Water Absorption in Horizontal Corrugated Boards Under Water Sprays, Fire Safety Journal, vol. 41, pp. 335-342, 2006.

[13] Zhou, X., D’Aniello, S. P. and Yu, H.Z., Spray Measurements of an Upright Fire Sprinkler, Fire Technology, December 2012. 